\title{
Current Status and Applications of Adaptive Laboratory Evolution in Industrial Microorganisms
}

\author{
SuRin Lee and Pil Kim* \\ Department of Biotechnology, the Catholic University of Korea, Gyeonggi 14662, Republic of Korea
}

\begin{abstract}
Adaptive laboratory evolution (ALE) is an evolutionary engineering approach in artificial conditions that improves organisms through the imitation of natural evolution. Due to the development of multi-level omics technologies in recent decades, ALE can be performed for various purposes at the laboratory level. This review delineates the basics of the experimental design of ALE based on several ALE studies of industrial microbial strains and updates current strategies combined with progressed metabolic engineering, in silico modeling and automation to maximize the evolution efficiency. Moreover, the review sheds light on the applicability of ALE as a strain development approach that complies with non-recombinant preferences in various food industries. Overall, recent progress in the utilization of ALE for strain development leading to successful industrialization is discussed.
\end{abstract}

Keywords: Industrial strain development, adaptive laboratory evolution, systems metabolic engineering

\section{Introduction}

As microorganisms are repeatedly subcultured in the laboratories, the lag phase is shortened and the growth rate is increased compared to the initial culture. This is the result of "struggling for existence", as Darwin stated. During the process of competing in an environment with limited resource, adaptive mutations are passed down, which bring about changes in the whole population. In this way, unintended evolution occurs over a short period. Adaptive laboratory evolution (ALE) is a narrow-experimental evolution that mimics this natural phenomenon in laboratory and derives the desired phenotype. It is possible to change the environment by applying artificial selection pressure and obtain the ameliorated organism generated by the accumulation of beneficial mutations via natural selection $[1,2]$. ALE was first used by the evolutionary scientist Dallinger in the seven-year hightemperature adaptation experiment [3] and has since been applied to studies on various organisms, from microalgae, mammalian cells, and viruses, to standard model organisms such as E. coli and yeast [4-9].

Efficient rational engineering of cellular metabolism is possible only if comprehensive knowledge of metabolic pathways is acquired; however, this aspect is elusive even in the most well-characterized model organism, E. coli. As coenzymes such as ATP, NADH, and NADPH are used in multiple metabolic reactions in common, complex interactions between metabolic reactions frequently impede strain improvement, resulting in different metabolic outcomes (e.g., sub-optimal growth, lower product concentration) $[6,10]$. Besides, practical difficulties arise when the genetic manipulation itself is complicated by polyploidy, gene essentiality, etc. ALE can overcome these limitations because it does not require prior knowledge of the genotype-phenotype relationship and is easy to implement practically. In particular, it is advantageous for inducing a counter-intuitive phenotype spanning numerous intracellular pathways such as diverse stress tolerances and rapid growth in specific environments. ALE has been used as a powerful complement to metabolic engineering by subsequently re-optimizing the cellular fitness of crippled recombinants $[11,12]$. In addition to the strain improvement, the omics approach for the analysis of causative mutations in growth-improved strains is used for expanding intracellular regulatory networks by revealing underlying mechanisms that regulate cell metabolism [6,13-16]. For example, transcriptome analysis of evolved E. coli with minimal genome showed that increasing the Entner-Doudoroff pathway flux, which enables efficient glucose utilization and increased intracellular reducing power, contributed to rapid growth [12]. Thus, ALE provides a straightforward reverse engineering approach that can overcome the shortcomings of existing rational metabolic engineering $[2,17]$.

Industrial microorganisms have long been exploited as key producers in almost every field, including food, pharmaceuticals, and other value-added chemical production. Efforts to eliminate obstacles and maximize productivity in bio-based processes are still ongoing, and ALE is one of the most effective approaches for this endeavor. In particular, microorganisms have the advantages like easy control of culture conditions, short generation time, easy manufacturing, and storage of living fossil records for each period [18]; therefore, research on microorganisms utilizing ALE has been actively conducted. Recently, a multi-disciplinary approach termed 
"systems metabolic engineering", which encompasses systems biology, synthetic biology, and evolutionary engineering with the existing metabolic engineering approaches, has paved the way for the industrial use of microbial ALE.

This review presents recent ALE studies on industrial microorganisms, major considerations for efficient experimental design, and highlights the utility of various tools and strategies for strain optimization.

\section{Empirical Studies of ALE for Industrial Application}

The development of industrial strains aims to maximize productivity (product formation in unit time) and yield (product formation per substrate consumption) [19]. For industrial process efficiency, ALE of an industrial host can contribute to cut down the cycle time and improve product titer, strain tolerance, and substrate utilization ability. Application of ALE for strain improvement is typically categorized as 1) optimization of growth on a specific nutrient and induction of prototrophy, 2) growing under harsh conditions (non-optimal $\mathrm{pH}$ and temperature) or tolerating adverse environment like inhibitors generated during the process, 3 ) production of new substances or increment of product titer.

Empirical ALE studies aimed for improved productivity of value-added products and substrate flexibility of strains were listed to identify the preferred production strain, the evolutionary duration, and conditions for each product. These include examples of E. coli, S. cerevisiae, C. glutamicum, microalgae, and Streptomyces sp., used for increasing production of metabolites and recombinant proteins that can be used in the pharmaceutical, food, bioplastic, and biofuel industries [8, 20-43]. The cases of adaptive evolution of E. coli, C. glutamicum, S. cerevisiae, and $G$. oxidans that enables economical bioconversion process by maximizing the utilization of relatively inexpensive substrate such as whey and biorenewable resources were also included. [9, 44-51]. Some detailed examples are discussed in the following sections.

\section{Practical Considerations of ALE}

There are several factors that the researcher should consider for successful ALE results. First, the mode of cultivation should be determined by considering the characteristics of the host strain, available man-power, and other costs incurred during the process. Batch and continuous culture are the two main methods of culturing microorganisms. As described in the review by Sandberg et al. [52], most of the ALE were performed using batch culture, which is simple to execute and requires no special apparatus, thus incurring less expenses. In addition, it is possible to observe a common mutation by reducing the culture volume to a small scale, such as 96 wells, or by increasing the number of replicates through automation [53]. This makes it possible to clearly identify the direction of evolution in a certain environment. However, the population density varies from flask to flask and the fluidity of the physico-chemical environment, including $\mathrm{pH}$ and dissolved oxygen, is difficult to keep constant due to changes in cell density that depend on the residual amount of nutrients [54]. This may lead to erroneous evolutionary pressure, which causes an undesired phenotype and makes it difficult to identify the relationship between the genotype and phenotype [55]. However, continuous culture maintains consistent environmental conditions, supplies nutrients, and manages to keep the cell density and growth rate constant [54-56]. There are also some disadvantages to this method. Since it has a long running time, it is difficult to maintain sterility and the stability of metabolic engineered strains, although mutation is helpful in terms of evolution [57]. There is also the possibility of biased evolution of mutants that have adhesive properties to prevent washing out [58]. Most of all, it is expensive to set up and operate, and it is hard to conduct in parallel. To reduce the cost and enable parallel operation, while taking advantage of continuous culture, miniaturization of the vessel can be an alternative route [59].

Second, it is essential to apply the appropriate selection pressure to screen the desired phenotype from the entire population. For the purpose of increasing the growth rate of organisms, maximizing the use of alternative carbon sources, harsh conditions (non-optimal $\mathrm{pH}$ and temperature), or tolerance for substances generated during production, the organisms favorable for survival in specific conditions reproduce rapidly and the desired phenotype and growth rate are coupled, facilitating screening. For example, overproducer of antimicrobial substances can be easily identified by superior cell viability in hostile environment $[39,40]$. However, the phenotype is sometimes not linked to an improvement in growth rate. Overproduction of growth-irrelevant metabolite or an evolution-induced altered mutation acts as a metabolic burden thus reducing the growth rate or biomass [60]. Therefore, metabolic pathways are adjusted to couple desired phenotypes to growth for growthbased selection. This method of applying artificial evolutionary pressure by metabolic engineering was proposed with the name "metabolic engineering-guided evolution (MGE)" [61]. Considerable numbers of the studies presented in Table 1 started with a mutant rather than a wild type strain, or a genetically modified mid-point strain, to prevent efflux of resources that interfere with production or to exert evolutionary pressure. However, in the process of MGE, prior knowledge for rational design is required, making its application limited to targeting well-known materials; it also may require complicated manipulation. In addition to MGE, as an alternative to screening growth-uncoupled phenotype, the transcription factor-based or riboswitch-based biosensors has recently emerged as detectors of intracellular substances not related to growth $[27,29,62]$. In the ALE study of $C$. glutamicum engineered for the production of L-valine, which was the first to propose this method [29], the cells expressing the downstream green fluorescent protein (GFP) reporter gene depending on whether the transcription factor (Lrp) binds to the promoter were sorted by fluorescence-activated cell sorting (FACS). The group showing strong fluorescence was isolated and cultivated in an iterative manner to induce evolution. In another instance, Choi et al. reported that it is possible to increase the production of a recombinant protein by 
Table 1. Adaptive laboratory evolutions of industrial microorganisms categorized by product and feedstock.

\begin{tabular}{|c|c|c|c|c|}
\hline Product & Species & Condition & Span & Reference \\
\hline \multicolumn{5}{|c|}{ Organic acid and amino acid } \\
\hline $\begin{array}{l}\text { Chirally pure } \\
\text { lactates }\end{array}$ & $\begin{array}{l}\text { E. coli SZ194, } \\
\Delta l d h A:: l d h L-F R T\end{array}$ & $\begin{array}{l}\text { Glucose minimal medium } \\
\text { containing betaine }\end{array}$ & up to 120 days & {$[20]$} \\
\hline Carboxylic acid & $\begin{array}{l}\text { E. coli MG1655, } \\
\Delta \text { fadD } \Delta \text { poxB } \triangle a c k A-p t a: c m R\end{array}$ & $\begin{array}{l}\text { MOPS minimal medium } \\
\text { with octanoic acid }\end{array}$ & $714 \mathrm{~h}$ & {$[21]$} \\
\hline D-lactic acid & $\begin{array}{l}\text { E. coli W strain } \\
\Delta p f l B \Delta p t a \Delta a d h E, \Delta f r d- \\
A B C D \Delta a l d A, \Delta C s c R\end{array}$ & LB or NBS medium & About 56 days & {$[22]$} \\
\hline L-lactic acid & $\begin{array}{l}\text { E. coli SZ470, } \\
\Delta a d h E \Delta l d h A:: l d h L\end{array}$ & LB-xylose medium & 3 months & {$[23]$} \\
\hline D-lactate & E. coli KO11 (ATCC 55124) & $10 \%$ glucose LB medium & About 12 days & {$[24]$} \\
\hline L-lactic acid & 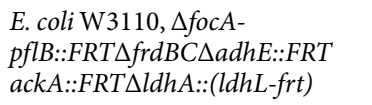 & GlcM9 medium & 12 days & {$[8]$} \\
\hline Succinic acid & $\begin{array}{l}\text { E. coli } \mathrm{K} 12 \Delta p t s G \Delta \operatorname{man} X \\
\text { E. coli } \mathrm{K} 12 \Delta p t s I\end{array}$ & LB medium & $48 \mathrm{~h}$ & {$[25]$} \\
\hline Succinic acid & $\begin{array}{l}\text { S. cerevisiae CEN.PK113-5D, } \\
\Delta s d h 3 \Delta \text { ser } 3 \Delta \text { ser } 33\end{array}$ & Gradually reducing glycine & $\mathrm{nd}^{*}$ & {$[26]$} \\
\hline Muconic acid & $\begin{array}{l}\text { S. cerevisiae BY } 4741, \\
\triangle \text { aro } 3 \triangle \text { aro } 4:: P G P D \text {-aro } 4_{k 229 l} \\
\text { Ty } 2 \delta:: P_{G P D^{-}} \\
\text {ECL_01944 } 4_{\text {opt }} \Delta z w f 1[115]\end{array}$ & $\begin{array}{l}\text { Geneticin and 4FP } \\
\text { (anti-metabolite) } \\
\text { containing medium }\end{array}$ & $1,325 \mathrm{~h}$ & {$[27]$} \\
\hline L-ornithin & $\begin{array}{l}\text { C. glutamicum ATCC } 13032 \text {, } \\
\Delta \text { argF } \triangle \text { proB } \triangle \text { speE }\end{array}$ & $\begin{array}{l}\text { Gradually reducing } \\
\text { ornithine }\end{array}$ & 70 days & {$[28]$} \\
\hline \multicolumn{5}{|c|}{ Alcohol } \\
\hline Ethanol & S. cerevisiae CEN.PK113-7D & Sucrose-limited chemostat & 90 generations & {$[30]$} \\
\hline Ethanol & $\begin{array}{l}\text { S. cerevisiae BY } 4741 \\
\text { expressing xylose isomerase } \\
\text { from B. cenocepacia }\end{array}$ & $\begin{array}{l}\text { YNB medium containing } \\
\text { xylose }\end{array}$ & 40 passages & {$[31]$} \\
\hline 1-Butanol & $\begin{array}{l}\text { E. coli JCL166, } \\
\Delta a d h E \Delta l d h A \Delta f r d B C\end{array}$ & $\begin{array}{l}\text { Conversion from LB } \\
\text { medium to M9 medium }\end{array}$ & $\mathrm{nd}^{*}$ & {$[32]$} \\
\hline Isobutanol & $\begin{array}{l}\text { E. coli JCL16 } \\
\text { NTG-created mutant }\end{array}$ & $\begin{array}{l}\text { GlcM9 medium with } \\
\text { norvaline (valine analog) }\end{array}$ & $\mathrm{nd}^{*}$ & {$[33]$} \\
\hline \multicolumn{5}{|c|}{ Lipid } \\
\hline Lipid & C. reinhardtii cc4324 derivatives & $\begin{array}{l}\text { Gradually reducing } \mathrm{NH}_{4} \mathrm{Cl} \\
\text { (nitrogen) }\end{array}$ & 84 days & {$[34]$} \\
\hline Lipid & R. opacus PD630 & $\begin{array}{l}\text { Gradually increasing } \\
\text { phenol concentration }\end{array}$ & 40 passages & {$[35]$} \\
\hline \multicolumn{5}{|c|}{ Pigment } \\
\hline Carotenoids & D. salina (UTEX LB \#200) & Blue light stress & $\begin{array}{l}16 \text { cycles } \\
\text { (each cycle was } \\
\text { conducted for } 5 \text { days) }\end{array}$ & {$[36]$} \\
\hline Lycopene & $\begin{array}{l}\text { E. coli MG1655 with plasmid } \\
\text { (lycopene synthase gene, } \\
\text { mutator module and sensor) }\end{array}$ & Designed by FREP & $432 \mathrm{~h}$ & {$[37]$} \\
\hline$\beta$-carotene & $\begin{array}{l}\text { S. cerevisiae GSY1136 strain } \\
{[116]}\end{array}$ & Hydrogen peroxide stress & about 40 days & {$[38]$} \\
\hline \multicolumn{5}{|c|}{ Antibacterial \& antifungal agent } \\
\hline $\begin{array}{l}\text { Antibacterial } \\
\text { compounds } \\
\text { against MRSA }\end{array}$ & S. clavuligerus 27064 & $\begin{array}{l}\text { Co-culture with methicillin } \\
\text { resistant S. aureus(MRSA) } \\
\text { N315 }\end{array}$ & About 90 days & [39] \\
\hline $\begin{array}{l}\text { Multiple } \\
\text { antifungal agents }\end{array}$ & S. variabilis AFP2 & $\begin{array}{l}\text { Co-culture with } C \text {. } \\
\text { neoformans } 14116\end{array}$ & 30 days & {$[40]$} \\
\hline \multicolumn{5}{|c|}{ ETC } \\
\hline Dihydroxyacetone & $\begin{array}{l}\text { E. coli strain C, } \triangle l d h A:: F R T, \\
\Delta a d h E:: F R T, \triangle a c k A:: F R T\end{array}$ & $\begin{array}{l}\text { NBS or AM1 medium with } \\
\text { glucose, gradually reducing } \\
\text { NaOAc }\end{array}$ & $\begin{array}{l}>2,000 \\
\text { generations }\end{array}$ & {$[41]$} \\
\hline $\begin{array}{l}\text { Improved } \\
\text { methyltransferases } \\
\text { (Mtases)activity }\end{array}$ & E. coli JW3582, $\Delta c y s E[117]$ & $\begin{array}{l}\text { M9 medium supplemented } \\
\text { with methionine and } \\
\text { substrates of Mtases }\end{array}$ & $\mathrm{nd}^{*}$ & {$[42]$} \\
\hline $\begin{array}{l}\text { Recombinant } \\
\text { protein }\end{array}$ & C. glutamicum ATCC 13032 & $\begin{array}{l}\text { 7-Times sorting by } \\
\text { measuring fluorescence }\end{array}$ & in 2 weeks & {$[43]$} \\
\hline
\end{tabular}

*nd-no data 
Table 1. Continued

\begin{tabular}{|c|c|c|c|c|}
\hline $\begin{array}{l}\text { Alternative } \\
\text { substrate }\end{array}$ & Species & Condition & Span & Reference \\
\hline \multicolumn{5}{|c|}{ Utilization of alternative carbon source } \\
\hline Lactose & S. cerevisiae NCYC869-A3/T1[118] & $\begin{array}{l}\text { Semisynthetic lactose } \\
\text { (SSlactose) medium, }\end{array}$ & $>120$ generations & {$[44]$} \\
\hline Xylose & $\begin{array}{l}\text { S. cerevisiae RWB } 217 \text { derived from } \\
\text { CEN.PK102-3A [119] }\end{array}$ & $\begin{array}{l}\text { Synthetic medium } \\
\text { with glucose and } \\
\text { xylose }\end{array}$ & $1,000 \mathrm{~h}$ & {$[45]$} \\
\hline \multicolumn{5}{|c|}{ Utilization of alternative carbon source } \\
\hline Xylose & $\begin{array}{l}\text { S. cerevisiae BY4741, } \Delta g r e 3, U R A:: G P D p- \\
x y l{ }^{*} 3-C Y C 1 t-T E F p X K S 1-C Y C 1 t, \text { Leu:: } \\
\text { GPDp-xylA*3-RPM1t-TEFp-tal1-CYC1t } \\
\text { YDL236w:: His }\end{array}$ & Xylose medium & 24 days & {$[46]$} \\
\hline $\begin{array}{l}\text { Xylose and } \\
\text { methanol }\end{array}$ & C. glutamicum ATCC 13032, derivatives & $\begin{array}{l}\text { CGXII medium with } \\
\text { xylose and methanol }\end{array}$ & 206 days & {$[47]$} \\
\hline Glucose & G. oxydans $621 \mathrm{H}$ recombinant $(m g d h:: G m)$ & Glucose medium & 50 days & {$[9]$} \\
\hline Glucose & G. oxydans strain evolved to use glucose [9] & Glucose medium & 25 days & {$[48]$} \\
\hline $\begin{array}{l}\text { Lactate or } \\
\text { glycerol }\end{array}$ & E. coli MG1655 & $\begin{array}{l}\text { M9 minimal } \\
\text { Medium with lactate } \\
\text { or glycerol }\end{array}$ & $>600$ generations & {$[49,50]$} \\
\hline 1,2-Propanediol & E. coli MG1655, GC strain [120] & $\begin{array}{l}\text { M9 minimal medium } \\
\text { with L-1,2- } \\
\text { propanediol }\end{array}$ & 700 generations & {$[51]$} \\
\hline
\end{tabular}

inducing a parB mutation that increases the copy number of the plasmid in the cell by sorting and passaging cells with increased GFP expression using FACS [43]. As such, the usability of biosensor-based high-throughput screening that enables straightforward and rapid screening is expected to increase in the future.

The third is the time span, that is, when to stop the ALE and obtain the final evolution product. Determining the end point is entirely up to the researcher's decision. Generally, due to the tendency for most causal mutations to fix early, beneficial mutation rates tend to decrease with longer evolutionary periods [63], although this does not mean that organisms stop adaptive evolution. A generation is generally the scale used to indicate the period of evolution, and days and transferred numbers are also displayed depending on the experimental method. Because of ambiguous criteria, it is difficult to compare experiments for evolutionary periods, even when the experiments evolve the same strain. For this reason, cumulative cell divisions (CCDs) have been proposed as a new time scale. CCD utilizes the total cumulative number of the whole population, which is substantially proportional to the mutation rate, as a denominator so that it can describe an accurate quantitative criterion for ALE's execution time [64].

Successful ALE results depend on the heterogeneity of the population resulting from mutations [19, 64]. Although artificial mutagenesis may induce mutation of the parent strain to increase diversity, adjusting the passage size (the amount of transferred cells) that can act as a bottleneck during serial transfer can also affect diversity [52]. It is also important to keep the cell state constant for each cycle. In addition, considering that the growth rate increases while the fitness increase decreases as the culture is prolonged, it seems trivial, but critical, to optimize the passage method, such as gradually increasing the passage frequency and reducing the passage size.

\section{Exploiting Genetic Engineering Tools to Assist Evolution}

ALE can be accompanied by genetic engineering to reconstruct metabolic pathways or to identify causality between mutations and phenotypic changes, as analyzed by WGS of evolutionary strains [61]. Classical metabolic engineering tools such as lambda red recombinase expression vector of $E$. coli and suicide vector (pKmobsacB) of C. glutamicum are widely used to introduce simple genetic changes in evolved strains $[12,65]$. The advent of the CRISPR (Clustered Regularly Interspaced Palindromic Repeats)-Cas (CRISPR-associated proteins) system, recognized as a new genome editing tool, has made manipulating genes easier and more sophisticated. In addition to direct genome disruptions such as point mutations, deletions, and insertions, combinatorial methods that use improved Cas proteins (dCas9) or even other fused enzymes, such as CRISPR interference (CRISPRi) [66] and CRISPR activation (CRISPRa) [67], have been developed to allow metabolic flux control. Recently, a prime editor that fuses transcriptase was developed [68], and the scope of various recombinant productions is being expanded.

The mutation rate in ALE is accelerated by population heterogeneity [69]. Therefore, to secure genetically diverse libraries, random mutagenesis of whole cells using mutagens, such as N-methyl-N'-nitro-Nnitrosoguanidine, ethyl methane sulfonate, can be performed using the same principle as the classical in vitro directed evolution $[33,70,71]$. However, the mutation rate increases in case of traditional in vivo mutagenesis, while the efficiency may decrease because of hitch-hiking (neutral, deleterious) and non-target mutations. These limitations can be overcome by targeted in vivo mutagenesis. Typical targeted in vivo mutagenesis includes an orthogonal replication pair (vector and DNA polymerase), ColE1/Pol [72], OrthoRep [73], and Muta T7 [74], which are composed of a phage-derived promoter, RNA polymerase, and DNA-damaging enzyme (cytidine 
deaminase). Because the characteristics of each method (applicable species and mutation introduction method) are different, it is important to use them properly according to the specific purpose. Furthermore, mutagenesis of the target sequence can be achieved using modified CRISPR-Cas technology such as EvolvR [75], CasPER [76], CREATE [77].

As to altering complex phenotypes, genome evolution approaches including genome shuffling [78], global transcription machinery engineering (gTME) [79], and MAGE (multiplex automated genome engineering) [80] are suitable. Sandberg et al. introduced several combinations of mutations in the starting strain using MAGE in the study of thermotolerant E. coli, enabling more efficient causative mutations and epistatic interactions [81]. Recently, novel in vivo continuous mutagenesis, genome replication engineering-assisted continuous evolution (GREACE) and feedback-regulated evolution of phenotype (FREP), which can generate mutations during evolution, have been developed. GREACE enables mutagenesis coupled with selection during evolution using DnaQ (the proofreading element of DNA polymerase) mutant library [82]. Luan et al., who first introduced this system, developed $n$-butanol, acetate-tolerant $E$. coli for biofuel production. Subsequently, Wang et al. increased the titer and yield of E. coli lysine by $14.8 \%$ and $9.3 \%$ using GREACE [83]. FREP is a synthetic gene circuit that detects product concentrations in vivo and regulates the mutation rate of the genome [37]. Chou et al., the inventors of FREP, increased tyrosine and lycopene yields in E. coli by approximately 5 and 3 times after $24 \mathrm{~h}$, respectively.

As these approaches are capable of mutation control, they can compensate for the disadvantages of the existing random mutagenesis, such as an unstable genotype and nonhomogeneous phenotype of the final strain; thus, they could be promising strategies for industrial strain development.

\section{ALE for Developing Non-Recombinant Strains}

Productivity and product quality may be degraded due to environments that are not suitable for growth, such as depletion of nutrients, low oxygen, and high osmolarity, which can occur on an industrial scale [84, 85]. Therefore, as stated above, ALE is often accompanied by genetic manipulation. However, unlike the production of fine chemicals without genetic materials, genetically modified microorganisms (GMMs) are rarely commercialized in traditional food and probiotics industries [86]. Apart from the definition of food-grade genetically modified organisms (GMOs) and the enactment of related laws, the production of GMO-derived food has been a constant debate due to the combination of negative consumer perceptions and distrust of conglomerates [87]. The use of GMMs, mostly composed of lactic acid bacteria and yeast, is disinclined because of the possibility of viable GMOs in the product to colonize during the digestive period in the human body, even if they pass through the stomach [88]. Although two genetically modified S. cerevisiae strains have been approved, the proportion of revenue they earn in the real market is expected to be negligible, and it is expected that it will take a long time for GMMs to become universal and affect the market [89].

Therefore, fermentation strains have been ameliorated through classical methods, such as random mutagenesis, and natural conjugation and transformation [90]. These methods are not subject to the strict regulations related to GMOs, but have the disadvantage that it is difficult to express brand-new characteristics not inherent in the strain. Furthermore, in the case of brewing yeast, sexual hybridization is intricate due to the loss of the spore-forming ability and sexual reproduction caused by industrial domestication [84, 91, 92], and random mutagenesis is also limited because of the complex genome structure of the production strain. This may also lead to the loss of the desired phenotype [89]. Experimental evolution is drawing attention as an efficient and nongenetic engineering technique that can solve these problems. In adaptive evolution, strain aneuploidy and polyploidy are not a problem $[93,94]$. Additionally, there is no need for the complicated work of screening strains of the desired phenotype and prior knowledge of genes involved in the attribute is not required [84]. For this reason, in the case of strains used in fermentation or probiotics, it is advantageous to improve varieties through ALE rather than genetic manipulation for commercialization.

However, there are limits to improvements without genetic modification. Several yeast studies have produced plant secondary metabolites through heterologous expression $[95,96]$, but relying only on evolution without external DNA sources cannot drive non-intrinsic pathways, thus limiting the development and production of new food flavors. This may lead to serious defects that do not lower unit costs. Another trepidation when using nonrecombinant is the difficulty in identifying the source of the production strain. A unique strain is the valuable original technology of the company. However, the non-recombinant strain is naturally derived from the ancestral wild type, and it can be difficult to distinguish clearly because there is no characteristic factor to distinguish the strain due to the absence of an artificial marker, which might lead a conflict of interests between industries. However, despite these shortcomings, at this point, where the GMO controversy has not easily faded for decades, the improvement of production strains using experimental evolution without the influx of external DNA is anticipated to be used as a reasonable and practical strategy to ensure stable profits.

\section{A Genome-Scale Metabolic Model for Insight into Integrated Cellular Systems}

The optimization of cell factories is an iterative process (design-build-test-learn [DBTL] cycle) consisting of strain construction, evaluation, and data analysis to obtain the desired product [97, 98]. In the process of constructing an overproducer, the collaboration of ALE with the genome-scale metabolic model (GEM) [10], one of several mathematical models describing metabolic processes, facilitates obtaining a desirable phenotype [99]. GEM is an in silico model derived from genome-scale network reconstruction (GENRE) based on an organismspecific biochemical, genetic, and genomic (BiGG) knowledge base, which converts network construction into 
Table 2. The latest genome-scale metabolic models of industrial platform strains.

\begin{tabular}{|c|c|c|c|c|}
\hline Organism & Main products/applications & Model & Description & Ref. \\
\hline E. coli K-12 MG1655 & $\begin{array}{l}\text { Biofuel, multipurpose } \\
\text { recombinant proteins }\end{array}$ & $i \mathrm{ML} 1515$ & $\begin{array}{l}1515 \text { Genes, } 2719 \text { reactions, } \\
1192 \text { metabolites }\end{array}$ & [120] \\
\hline S. cerevisiae & $\begin{array}{l}\text { Alcoholic beverages, bakery } \\
\text { products and bioethanol }\end{array}$ & $\begin{array}{l}\text { Yeast8 } \\
\text { ecYeast8 } \\
\text { panYeast8 } \\
\text { coreYeast8 } \\
\text { proYeast8 }\end{array}$ & $\begin{array}{l}1133 \text { Genes, } 3949 \text { reactions, } \\
2680 \text { metabolites }\end{array}$ & [121] \\
\hline $\begin{array}{l}\text { C. glutamicum } \\
\text { ATCC13032 }\end{array}$ & Amino acids & iCW773 & $\begin{array}{l}773 \text { Genes, } 1207 \text { reactions, } \\
950 \text { metabolites }\end{array}$ & [122] \\
\hline B. subtilis & $\begin{array}{l}\text { Industrial enzymes and } \\
\text { antibiotics }\end{array}$ & $i$ Bsu1144 & $\begin{array}{l}1144 \text { Genes, } 1955 \text { reactions, } \\
1103 \text { metabolites }\end{array}$ & [123] \\
\hline Alternaria sp. MG1 & Resveratrol & iYL1539 & $\begin{array}{l}1539 \text { Genes, } 2255 \text { reactions, } \\
2231 \text { metabolites }\end{array}$ & [124] \\
\hline S. coelicolor & $\begin{array}{l}\text { Antibiotics and secondary } \\
\text { metabolites }\end{array}$ & $\begin{array}{l}\text { Sco-GEM } \\
\text { EcSco-GEM }\end{array}$ & $\begin{array}{l}1777 \text { Genes, } 2612 \text { reactions, } \\
2073 \text { metabolites }\end{array}$ & [125] \\
\hline C. vulgaris & $\begin{array}{l}\text { Lipids and pigments for biofuel } \\
\text { and food supplements }\end{array}$ & iCZ946 & $\begin{array}{l}946 \text { Genes, } 2,294 \text { reactions, and } \\
1,770 \text { metabolites }\end{array}$ & [126] \\
\hline $\begin{array}{l}\text { L. mesenteroides } \\
\text { subsp. cremoris ATCC } \\
19254\end{array}$ & $\begin{array}{l}\text { Used as a starter in food } \\
\text { fermentation (dairy, meat, } \\
\text { vegetable product) }\end{array}$ & iLM.c559 & $\begin{array}{l}559 \text { Genes, } 1088 \text { reactions, } \\
1129 \text { metabolites }\end{array}$ & [127] \\
\hline L. reuteri JCM 1112 & $\begin{array}{l}\text { Used as a starter in food } \\
\text { fermentation and used in } \\
\text { probiotic product, reuterin }\end{array}$ & Lreuteri_530 & $\begin{array}{l}530 \text { Genes, } 710 \text { reactions, } \\
658 \text { metabolites }\end{array}$ & [128] \\
\hline N. salina & $\begin{array}{l}\text { Lipids and pigments for biofuel } \\
\text { and food supplements }\end{array}$ & $i$ NS934 & $\begin{array}{l}934 \text { Genes, } 2345 \text { reactions, } \\
1985 \text { metabolites }\end{array}$ & [129] \\
\hline C. reinhardtii & Biofuel & $\mathrm{nd}^{*}$ & 3726 Reactions, 2436 metabolites & [130] \\
\hline
\end{tabular}

*nd-no data

mathematical forms to computationally assess phenotypic properties [100]. Beginning with Haemophilus influenza [101], GEMs of various species have been constructed to date, and after repeated development, a more sophisticated level of model prediction is now possible (Table 2) [102]. These models contain information on gene products involved in metabolic reactions, as well as stoichiometric information of all metabolic reactions in cells; hence the entire network of life [10,63]. Therefore, GEMs show the correlation between genotype and phenotype and can be used to predict physiological changes, such as cellular redox state or energy metabolism according to the theoretical maximum yield of product and genome perturbation. By using GEM, Otero et al. made it possible to guide the experimental direction by predicting in silico gene deletion in evolutionary engineering combining $S$. cerevisiae biomass and succinate production [26]. They identified the target gene to be deleted using the OptGene algorithm to couple the objective function (improved succinate production) and biomass. In order to prevent succinate consumption within the TCA cycle and serine synthesis metabolism flux from glycolysis, sdh3, ser3, ser33 were knocked out, and the subsequent ALE finally yielded a 7.7-fold increase in succinate yield glycine prototroph. Likewise, in the study of adaptation against substrate alteration by Sandberg et al., it could be explained why the specialist subpopulation arises on glucose/acetate switching, based on discrepancy in reaction fluxes through the simulation of individual metabolic fluxes [103].

Furthermore, GEM and ALE can also be used together to derive the desired phenotype. In contrast with in silico experimental predictions, the desired outcome is often elusive to attain (e.g., high-yield production) in vivo, due to the high degree of connectivity between diverse pathways within the cellular system and not considering a large number of regulatory constraints in GEM [10]. Through the ALE experiment, the latent potential of the production host can be realized, and the knowledge obtained from the results of omics data analysis can be used to refine the design again to complement the results. Ibarra et al. performed ALE to resolve inconsistencies between in silico prediction and actual experimental results of $E$. coli growth rate when glycerol was provided as the sole carbon source, enabling the yield of theoretical optimal growth results [11]. In recent years, since attempts have been made to integrate not only metabolic processes in GEM, but also information about proteins (structure, synthesis, and secretion pathways), prediction through modeling is expected to be more accurate $[10,19]$.

\section{Automation of ALE}

In the process of manual cultivation for a long time, several practical problems arise. First, it is very laborious to continuously and frequently monitor cells during long-term experiments. Since most ALEs are performed for increasing growth rates, the monitoring intervals should be shorter as cells evolve to accurately measure growth rates; however, there are limitations to such manual approach. In addition, the batch culture used in many ALE studies is more strenuous and error-prone because additional manual processes, such as periodic passage, are required. These problems can be dealt with by the introduction of full or partial automation. For example, using a machine, the passage of batch culture can be performed at a frequency 3-7 times higher than the manual process, so it is not restricted by the experimenter's schedule, allowing passage at a constant growth stage and reducing 


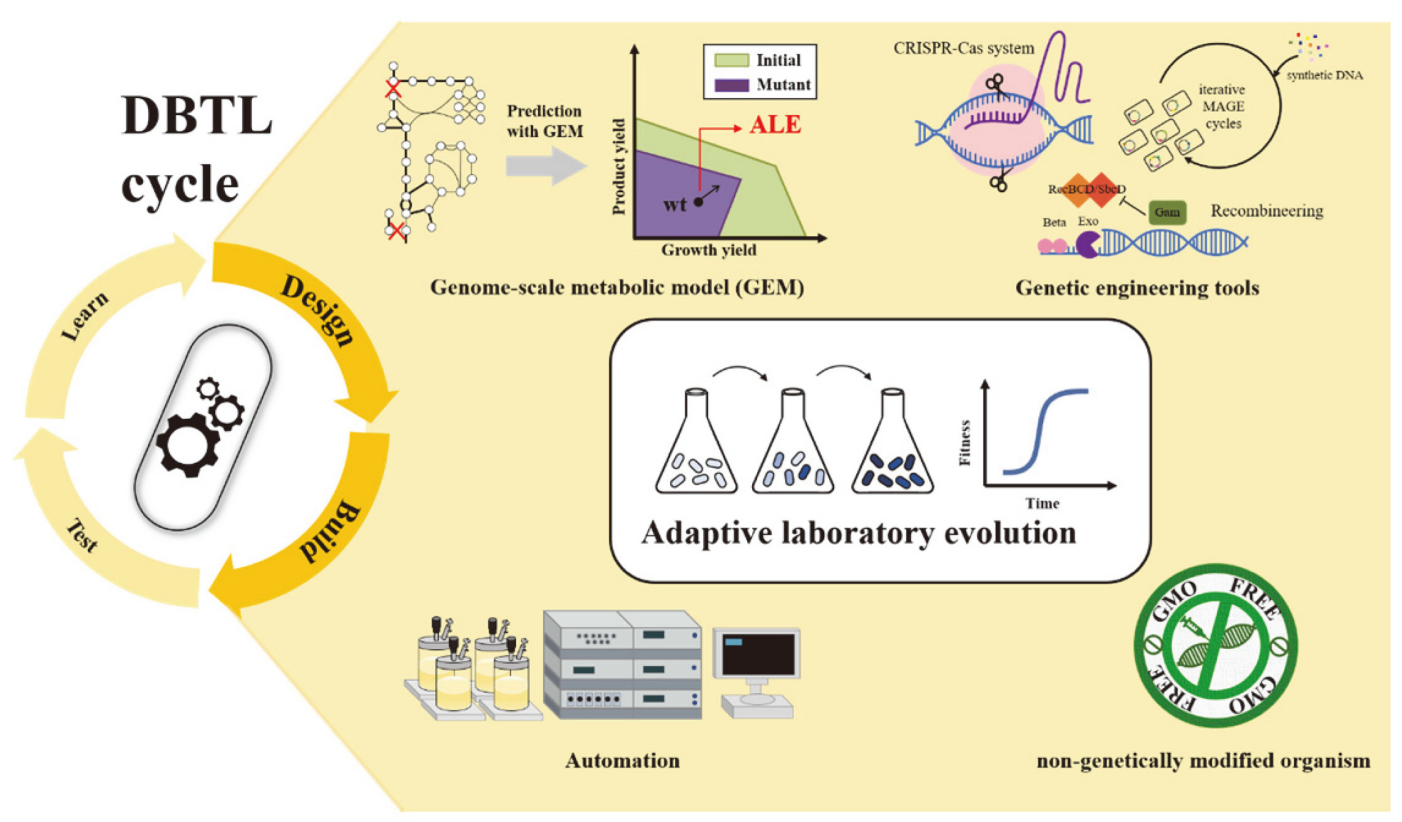

Fig. 1. Recent progress in tools and strategies for ALE. Adaptive laboratory evolution (ALE) is one of the most preferred approaches to optimize host in the design-build-test-learn (DBTL) cycle. It elicits desired outcome efficiently along with genome-scale metabolic model, genetic engineering tools and computational technology as well as aids the amelioration of non-recombinant strain in the food industry. CRISPR-Cas system, Clustered Regularly Interspaced Palindromic RepeatsCRISPR-associated proteins system; MAGE, multiplex automated genomic engineering.

fluctuation of passage size. This can prevent beneficial mutation loss [104, 105]. The problem of maintaining exponential growth and the appropriate selective pressure level can also be solved, unwanted effects caused by manual adjustment can be minimized, and genetic diversity can be secured, resulting in a shorter time to obtain an endpoint. In addition, it is possible to consolidate statistical significance by increasing the number of independent replicates beyond the capacity of a person to perform [16], readily introducing changes in the culture environment (substrate gradients, temperature, etc.) and monitoring the status in real time. Accordingly, ALE studies that automate repetitive batch cultivation processes have been continuously reported [59, 81, 106-108]. By measuring the optical density (OD), cell growth status can be checked and then automatically passed to the next vessel at the right time to take advantage of the aforementioned, as well as to measure the $\mathrm{pH}$ and dissolved oxygen in real-time to monitor the immediate response of the cells to the environment. There are also types of machinery that enhance the automatic aspect of continuous culture. An morbidostat can detect a population increase and adjust the levels of chemicals acting as the selection pressure, as feedback. A fluorostat, which combines fluorescence detection with a turbidostat, can be applied to determine gene expression levels [109-111]. Recently, eVOLVER, a framework consisting of open-source software and flexible hardware that can customize experimental conditions according to a specific purpose, was developed. It was introduced as a tool that can be reconfigured in the laboratory, and a detailed user guide to operate this platform is provided $[112,113]$. High-throughput cultivation techniques can be used to derive the outcome of experimental evolution more quickly and accurately, and the acquired knowledge and outcomes can be used industrially, such as improved understanding of bioprocessing and the resulting improved strains. However, considering that most of the automated systems introduced above are laboratory scales of $\mu \mathrm{L}$ and $\mathrm{mL}$, verification through scale-up is required.

\section{Conclusion}

In conclusion, connecting a theoretical study directly to the success of industrialization remains a challenging task. The fragmentary knowledge of host metabolic pathways is insufficient to predict the downstream effects caused by the complex network in the cell. The scale of the culture and the industrial process at the laboratory level are different, which is also a major factor that hampers the practical use of the developed strain. Thus, it is inevitable that considerable trials and errors in the process of constructing a microbial cell factory are conducted. The point is that this series of processes should not just end in failure, but it is the interpretation of the results that should complement the underlying knowledge and reduce the development process itself, resulting in cost savings and industrial competitiveness. In this regard, ALE combined with systems biology and synthetic biology tools is a prominent strategy that can be used in the design and build steps of the Design-Build-Test-Learn (DBTL) cycle for microbial strain development (Fig. 1). The in silico metabolic model allows organic connectivity of the testing, building, testing and learning with a more in-depth analysis of the integrated cell system perspective using WGS and omics analysis data. In addition, automation and high-throughput screening of ALE have made more accurate and rapid development and detection possible. In this context, the multi-disciplinary toolboxes 
applicable for the efficiency of the development process will continue to be developed, and the base knowledge of various species should also be expanded so as not to be limited to a few platform species.

\section{Acknowledgments}

This work was financially supported by the grants from the National Research Foundation of Korea (2016R1E1A1A01943552). KP appreciates the support from the research fund 2018 from the CUK.

\section{Conflict of Interest}

The authors have no financial conflicts of interest to declare.

\section{References}

1. Phaneuf PV, Gosting D, Palsson BO, Feist AM. 2019. ALEdb 1.0: a database of mutations from adaptive laboratory evolution experimentation. Nucleic Acids Res. 47: D1164-D1171.

2. Shepelin D, Hansen ASL, Lennen R, Luo H, Herrgard MJ. 2018. Selecting the best: evolutionary engineering of chemical production in microbes. Genes (Basel) 9: 249.

3. Bennett AF, Hughes BS. 2009. Microbial experimental evolution. 297: R17-R25

4. Kering KK, Zhang X, Nyaruaba R, Yu J, Wei H. 2020. Application of adaptive evolution to improve the stability of bacteriophages during storage. Viruses 12: E423.

5. Bailey LA, Hatton D, Field R, Dickson AJ. 2012. Determination of Chinese hamster ovary cell line stability and recombinant antibody expression during long-term culture. Biotechnol. Bioeng. 109: 2093-2103.

6. Cakar ZP, Turanli-Yildiz B, Alkim C, Yilmaz U. 2012. Evolutionary engineering of Saccharomyces cerevisiae for improved industrially important properties. FEMS Yeast Res. 12: 171-182.

7. Stella RG, Wiechert J, Noack S, Frunzke J. 2019. Evolutionary engineering of Corynebacterium glutamicum. Biotechnol. J. 14: e1800444.

8. Zhou S, Shanmugam KT, Ingram LO. 2003. Functional replacement of the Escherichia coli D-(-)-lactate dehydrogenase gene (ldhA) with the L-(+)-lactate dehydrogenase gene (ldhL) from Pediococcus acidilactici. Appl. Environ. Microbiol. 69: 2237-2244.

9. Zhu K, Lu L, Wei L, Wei D, Imanaka T, Hua Q. 2011. Modification and evolution of Gluconobacter oxydans for enhanced growth and biotransformation capabilities at low glucose concentration. Mol. Biotechnol. 49: 56-64.

10. Nielsen J. 2017. Systems biology of metabolism. Annu. Rev. Biochem. 86: 245-275.

11. Ibarra RU, Edwards JS, Palsson BO. 2002. Escherichia coli K-12 undergoes adaptive evolution to achieve in silico predicted optimal growth. Nature 420: 186-189.

12. Choe D, Lee JH, Yoo M, Hwang S, Sung BH, Cho S, et al. 2019. Adaptive laboratory evolution of a genome-reduced Escherichia coli. Nat. Commun. 10: 935

13. Si T, Lian J, Zhao H. 2017. Strain Development by Whole-Cell Directed Evolution, pp. 173-200. In Alcalde M (ed.), Directed Enzyme Evolution: Advances and Applications, Ed. Springer International Publishing, Cham

14. Conrad TM, Lewis NE, Palsson BØ. 2011. Microbial laboratory evolution in the era of genome-scale science. Mol. Syst. Biol. 7: 509509.

15. Portnoy VA, Bezdan D, Zengler K. 2011. Adaptive laboratory evolution-harnessing the power of biology for metabolic engineering. Curr. Opin. Biotechnol. 22: 590-594.

16. Winkler JD, Kao KC. 2014. Recent advances in the evolutionary engineering of industrial biocatalysts. Genomics 104: 406-411.

17. Winkler J, Reyes LH, Kao KC. 2013. Adaptive laboratory evolution for strain engineering. Methods Mol. Biol. 985: $211-222$.

18. Elena SF, Lenski RE. 2003. Evolution experiments with microorganisms: the dynamics and genetic bases of adaptation. Nat. Rev. Genet. 4: 457-469.

19. Choi KR, Jang WD, Yang D, Cho JS, Park D, Lee SY. 2019. Systems metabolic engineering strategies: Integrating systems and synthetic biology with metabolic engineering. Trends Biotechnol. 37: 817-837.

20. Grabar TB, Zhou S, Shanmugam KT, Yomano LP, Ingram LO. 2006. Methylglyoxal bypass identified as source of chiral contamination in $\mathrm{l}(+)$ and d(-)-lactate fermentations by recombinant Escherichia coli. Biotechnol. Lett. 28: 1527-1535.

21. Royce LA, Yoon JM, Chen Y, Rickenbach E, Shanks JV, Jarboe LR. 2015. Evolution for exogenous octanoic acid tolerance improves carboxylic acid production and membrane integrity. Metab. Eng. 29: 180-188.

22. Wang Y, Tian T, Zhao J, Wang J, Yan T, Xu L, et al. 2012. Homofermentative production of D-lactic acid from sucrose by a metabolically engineered Escherichia coli. Biotechnol. Lett. 34: 2069-2075.

23. Zhao J, Xu L, Wang Y, Zhao X, Wang J, Garza E, et al. 2013. Homofermentative production of optically pure L-lactic acid from xylose by genetically engineered Escherichia coli B. Microb. Cell Fact. 12: 57.

24. Zhou S, Yomano LP, Shanmugam KT, Ingram LO. 2005. Fermentation of $10 \%$ (w/v) sugar to D: (-)-lactate by engineered Escherichia coli B. Biotechnol. Lett. 27: 1891-1896.

25. Kim HJ, Jeong H, Lee SJ. 2020. Short-term adaptation modulates anaerobic metabolic flux to succinate by activating ExuT, a novel D-glucose transporter in Escherichia coli. Front. Microbiol. 11: 27.

26. Otero JM, Cimini D, Patil KR, Poulsen SG, Olsson L, Nielsen J. 2013. Industrial systems biology of Saccharomyces cerevisiae enables novel succinic acid cell factory. PLoS One 8: e54144.

27. Leavitt JM, Wagner JM, Tu CC, Tong A, Liu Y, Alper HS. 2017. Biosensor-enabled directed evolution to improve muconic acid production in Saccharomyces cerevisiae. Biotechnol. J. 12(10). doi: 10.1002/biot.201600687.

28. Jiang LY, Chen SG, Zhang YY, Liu JZ. 2013. Metabolic evolution of Corynebacterium glutamicum for increased production of Lornithine. BMC Biotechnol. 13: 47 .

29. Mahr R, Gatgens C, Gatgens J, Polen T, Kalinowski J, Frunzke J. 2015. Biosensor-driven adaptive laboratory evolution of L-valine production in Corynebacterium glutamicum. Metab. Eng. 32: 184-194.

30. Basso TO, de Kok S, Dario M, do Espirito-Santo JC, Muller G, Schlolg PS, et al. 2011. Engineering topology and kinetics of sucrose metabolism in Saccharomyces cerevisiae for improved ethanol yield. Metab. Eng. 13: 694-703.

31. Vilela Lde F, de Araujo VP, Paredes Rde S, Bon EP, Torres FA, Neves BC, et al. 2015. Enhanced xylose fermentation and ethanol production by engineered Saccharomyces cerevisiae strain. AMB Express. 5: 16.

32. Pontrelli S, Fricke RCB, Sakurai SSM, Putri SP, Fitz-Gibbon S, Chung M, et al. 2018. Directed strain evolution restructures metabolism for 1-butanol production in minimal media. Metab. Eng. 49: 153-163.

33. Smith KM, Liao JC. 2011. An evolutionary strategy for isobutanol production strain development in Escherichia coli. Metab. Eng. 13: 674-681. 
34. Yu S, Zhao Q, Miao X, Shi J. 2013. Enhancement of lipid production in low-starch mutants Chlamydomonas reinhardtii by adaptive laboratory evolution. Bioresour. Technol. 147: 499-507.

35. Yoneda A, Henson WR, Goldner NK, Park KJ, Forsberg KJ, Kim SJ, et al. 2016. Comparative transcriptomics elucidates adaptive phenol tolerance and utilization in lipid-accumulating Rhodococcus opacus PD630. Nucleic Acids Res. 44: 2240-2254.

36. Fu W, Guethmundsson O, Paglia G, Herjolfsson G, Andresson OS, Palsson BO, et al. 2013. Enhancement of carotenoid biosynthesis in the green microalga Dunaliella salina with light-emitting diodes and adaptive laboratory evolution. Appl. Microbiol. Biotechnol. 97: 2395-2403.

37. Chou HH, Keasling JD. 2013. Programming adaptive control to evolve increased metabolite production. Nat. Commun. 4: 2595.

38. Reyes LH, Gomez JM, Kao KC. 2014. Improving carotenoids production in yeast via adaptive laboratory evolution. Metab. Eng. 21: 26-33.

39. Charusanti P, Fong NL, Nagarajan H, Pereira AR, Li HJ, Abate EA, et al. 2012. Exploiting adaptive laboratory evolution of Streptomyces clavuligerus for antibiotic discovery and overproduction. PLoS One 7: e33727.

40. Rathore SS, Ramamurthy V, Allen S, Selva Ganesan S, Ramakrishnan J. 2016. Novel approach of adaptive laboratory evolution: Triggers defense molecules in Streptomyces sp. against targeted pathogen. RSC Adv. 6: 96250-96262.

41. Jantama K, Haupt MJ, Svoronos SA, Zhang X, Moore JC, Shanmugam KT, et al. 2008. Combining metabolic engineering and metabolic evolution to develop nonrecombinant strains of Escherichia coli C that produce succinate and malate. Biotechnol. Bioeng. 99: 1140-1153.

42. Luo H, Hansen ASL, Yang L, Schneider K, Kristensen M, Christensen U, et al. 2019. Coupling S-adenosylmethionine-dependent methylation to growth: design and uses. PLoS Biol. 17: e2007050.

43. Choi JW, Yim SS, Jeong KJ. 2018. Development of a high-copy-number plasmid via adaptive laboratory evolution of Corynebacterium glutamicum. Appl. Microbiol. Biotechnol. 102: 873-883.

44. Guimaraes PM, Francois J, Parrou JL, Teixeira JA, Domingues L. 2008. Adaptive evolution of a lactose-consuming Saccharomyces cerevisiae recombinant. Appl. Environ. Microbiol. 74: 1748-1756.

45. Kuyper M, Toirkens MJ, Diderich JA, Winkler AA, van Dijken JP, Pronk JT. 2005. Evolutionary engineering of mixed-sugar utilization by a xylose-fermenting Saccharomyces cerevisiae strain. FEMS Yeast Res. 5: 925-934.

46. Lee SM, Jellison T, Alper HS. 2014. Systematic and evolutionary engineering of a xylose isomerase-based pathway in Saccharomyces cerevisiae for efficient conversion yields. Biotechnol. Biofuels. 7: 122 .

47. Tuyishime P, Wang Y, Fan L, Zhang Q, Li Q, Zheng P, et al. 2018. Engineering Corynebacterium glutamicum for methanoldependent growth and glutamate production. Metab. Eng. 49: 220-231.

48. Lu L, Wei L, Zhu K, Wei D, Hua Q. 2012. Combining metabolic engineering and adaptive evolution to enhance the production of dihydroxyacetone from glycerol by Gluconobacter oxydans in a low-cost way. Bioresour. Technol. 117: 317-324.

49. Fong SS, Joyce AR, Palsson BO. 2005. Parallel adaptive evolution cultures of Escherichia coli lead to convergent growth phenotypes with different gene expression states. Genome Res. 15: 1365-1372.

50. Hua Q, Joyce AR, Palsson BO, Fong SS. 2007. Metabolic characterization of Escherichia coli strains adapted to growth on lactate. Appl. Environ. Microbiol. 73: 4639-4647.

51. Lee DH, Palsson BO. 2010. Adaptive evolution of Escherichia coli K-12 MG1655 during growth on a nonnative carbon source, L1,2-propanediol. Appl. Environ. Microbiol. 76: 4158-4168.

52. Sandberg TE, Salazar MJ, Weng LL, Palsson BO, Feist AM. 2019. The emergence of adaptive laboratory evolution as an efficient tool for biological discovery and industrial biotechnology. Metab. Eng. 56: 1-16.

53. Dragosits M, Mattanovich D. 2013. Adaptive laboratory evolution - principles and applications for biotechnology. Microb. Cell Fact. 12: 64 .

54. Graf M, Haas T, Muller F, Buchmann A, Harm-Bekbenbetova J, Freund A, et al. 2019. Continuous adaptive evolution of a fastgrowing Corynebacterium glutamicum strain independent of protocatechuate. Front. Microbiol. 10: 1648.

55. Hoskisson PA, Hobbs G. 2005. Continuou culture - making a comeback? Microbiology 151: 3153-3159.

56. Jin T, Chen Y, Jarboe LR. 2016. Chapter 10 - Evolutionary methods for improving the production of biorenewable fuels and chemicals, pp. 265-290. In Eckert CA, Trinh CT (eds.), Biotechnology for Biofuel Production and Optimization, Ed. Elsevier, Amsterdam

57. Herbert D, Elsworth R, Telling RC. 1956. The continuous culture of bacteria; a theoretical and experimental study. J. Gen. Microbiol. 14: 601-622.

58. Rao VSH, Rao PRS. 2004. Global stability in chemostat models involving time delays and wall growth. Nonlinear Analysis: Real World Applications. 5: 141-158.

59. Radek A, Tenhaef N, Muller MF, Brusseler C, Wiechert W, Marienhagen J, et al. 2017. Miniaturized and automated adaptive laboratory evolution: evolving Corynebacterium glutamicum towards an improved d-xylose utilization. Bioresour. Technol. 245: 1377-1385.

60. Wu G, Yan Q, Jones JA, Tang YJ, Fong SS, Koffas MAG. 2016. Metabolic burden: cornerstones in synthetic biology and metabolic engineering applications. Trends Biotechnol. 34: 652-664.

61. Schwentner A, Feith A, Munch E, Busche T, Ruckert C, Kalinowski J, et al. 2018. Metabolic engineering to guide evolution - creating a novel mode for L-valine production with Corynebacterium glutamicum. Metab. Eng. 47: 31-41.

62. Lee S-W, Oh M-K. 2015. A synthetic suicide riboswitch for the high-throughput screening of metabolite production in Saccharomyces cerevisiae. Metab. Eng. 28: 143-150.

63. Palsson BO. 2015. Adaptive Laboratory Evolution, pp. 422-437. Systems Biology: Constraint-based Reconstruction and Analysis, Ed. Cambridge University Press, Cambridge

64. Lee DH, Feist AM, Barrett CL, Palsson BO. 2011. Cumulative number of cell divisions as a meaningful timescale for adaptive laboratory evolution of Escherichia coli. PLoS One 6: e26172.

65. Pfeifer E, Gatgens C, Polen T, Frunzke J. 2017. Adaptive laboratory evolution of Corynebacterium glutamicum towards higher growth rates on glucose minimal medium. Sci. Rep. 7: 16780 .

66. Larson MH, Gilbert LA, Wang X, Lim WA, Weissman JS, Qi LSJNp. 2013. CRISPR interference (CRISPRi) for sequence-specific control of gene expression. Nat. Protoc. 8: 2180-2196.

67. Perez-Pinera P, Kocak DD, Vockley CM, Adler AF, Kabadi AM, Polstein LR, et al. 2013. RNA-guided gene activation by CRISPRCas9-based transcription factors. Nat. Methods 10: 973-976.

68. Anzalone AV, Randolph PB, Davis JR, Sousa AA, Koblan LW, Levy JM, et al. 2019. Search-and-replace genome editing without double-strand breaks or donor DNA. Nature 576: 149-157.

69. Bódi Z, Farkas Z, Nevozhay D, Kalapis D, Lázár V, Csörgő B, et al. 2017. Phenotypic heterogeneity promotes adaptive evolution. PLoS Biol. 15: e2000644-e2000644.

70. Sen M, Yilmaz U, Baysal A, Akman S, Cakar ZP. 2011. In vivo evolutionary engineering of a boron-resistant bacterium: Bacillus boroniphilus. Antonie van Leeuwenhoek. 99: 825-835.

71. Sonderegger M, Sauer U. 2003. Evolutionary engineering of Saccharomyces cerevisiae for anaerobic growth on xylose. Appl. Environ. Microbiol. 69: 1990-1998. 
72. Camps M, Naukkarinen J, Johnson BP, Loeb LA. 2003. Targeted gene evolution in Escherichia coli using a highly error-prone DNA polymerase I. 100: 9727-9732.

73. Ravikumar A, Arzumanyan GA, Obadi MKA, Javanpour AA, Liu CC. 2018. Scalable, continuous evolution of genes at mutation rates above genomic error thresholds. Cell 175: 1946-1957.e1913.

74. Moore CL, Papa LJ, 3rd, Shoulders MD. 2018. A processive protein chimera introduces mutations across defined DNA regions in vivo. J. Am. Chem. Soc. 140: 11560-11564.

75. Halperin SO, Tou CJ, Wong EB, Modavi C, Schaffer DV, Dueber JE. 2018. CRISPR-guided DNA polymerases enable diversification of all nucleotides in a tunable window. Nature 560: 248-252.

76. Jakočiūnas T, Pedersen LE, Lis AV, Jensen MK, Keasling JD. 2018. CasPER, a method for directed evolution in genomic contexts using mutagenesis and CRISPR/Cas9. Metab. Eng. 48: 288-296.

77. Garst AD, Bassalo MC, Pines G, Lynch SA, Halweg-Edwards AL, Liu R, et al. 2017. Genome-wide mapping of mutations at singlenucleotide resolution for protein, metabolic and genome engineering. Nat. Biotechnol. 35: 48-55.

78. Zhang Y-X, Perry K, Vinci VA, Powell K, Stemmer WPC, del Cardayré SB. 2002. Genome shuffling leads to rapid phenotypic improvement in bacteria. Nature 415: 644-646.

79. Alper H, Stephanopoulos G. 2007. Global transcription machinery engineering: a new approach for improving cellular phenotype. Metab. Eng. 9: 258-267.

80. Wang HH, Isaacs FJ, Carr PA, Sun ZZ, Xu G, Forest CR, et al. 2009. Programming cells by multiplex genome engineering and accelerated evolution. Nature 460: 894-898.

81. Sandberg TE, Pedersen M, LaCroix RA, Ebrahim A, Bonde M, Herrgard MJ, et al. 2014. Evolution of Escherichia coli to $42^{\circ} \mathrm{C}$ and subsequent genetic engineering reveals adaptive mechanisms and novel mutations. Mol. Biol. Evol. 31: 2647-2662.

82. Luan G, Cai Z, Li Y, Ma Y. 2013. Genome replication engineering assisted continuous evolution (GREACE) to improve microbial tolerance for biofuels production. Biotechnol. Biofuels. 6: 137.

83. Wang X, Li Q, Sun C, Cai Z, Zheng X, Guo X, et al. 2019. GREACE-assisted adaptive laboratory evolution in endpoint fermentation broth enhances lysine production by Escherichia coli. Microb. Cell Fact. 18: 106.

84. McBryde C, Gardner JM, de Barros Lopes M, Jiranek V. 2006. Generation of Novel Wine Yeast Strains by Adaptive Evolution. Am. J. Enol. Vitic. 57: 423

85. Pérez-Torrado R, Querol A, Guillamón JM. 2015. Genetic improvement of non-GMO wine yeasts: strategies, advantages and safety. Trends Food Sci. Technol. 45: 1-11.

86. Börner RA, Kandasamy V, Axelsen AM, Nielsen AT, Bosma EF. 2019. Genome editing of lactic acid bacteria: opportunities for food, feed, pharma and biotech. FEMS Microbiol. Lett. 366: fny291.

87. Lusk JL, Roosen J, Bieberstein A. 2014. Consumer acceptance of new food technologies: causes and roots of controversies. Annu. Rev. Resour. Econ. 6: 381-405.

88. Høier E, Janzen T, Rattray F, Sørensen K, Børsting MW, Brockmann E, et al. 2010. The production, application and action of lactic cheese starter cultures, pp. 166-192. Technology of Cheesemaking, Ed.

89. Gonzalez R, Tronchoni J, Quirós M, Morales P. 2016. Genetic improvement and genetically modified microorganisms, pp. 71-96. Wine Safety, Consumer Preference, and Human Health, Ed. Springer

90. Csutak O, Sarbu I. 2018. Chapter 6 - Genetically Modified Microorganisms: Harmful or Helpful?, pp. 143-175. In Holban AM, Grumezescu AM (eds.), Genetically Engineered Foods, Ed. Academic Press

91. Snow R. 1983. Genetic improvement of wine yeast, pp. 439-459. Yeast genetics, Ed. Springe

92. Walker ME, Gardner JM, Vystavelova A, McBryde C, de Barros Lopes M, Jiranek VJFyr. 2003. Application of the reuseable, KanMX selectable marker to industrial yeast: construction and evaluation of heterothallic wine strains of Saccharomyces cerevisiae, possessing minimal foreign DNA sequences. 4: 339-347.

93. Bakalinsky AT, Snow R. 1990. The chromosomal constitution of wine strains of Saccharomyces cerevisiae. Yeast 6: 367-382

94. Querol A, Fernandez-Espinar MT, del Olmo M, Barrio E. 2003. Adaptive evolution of wine yeast. Int. J. Food Microbiol. 86: 3-10.

95. Denby CM, Li RA, Vu VT, Costello Z, Lin W, Chan LJG, et al. 2018. Industrial brewing yeast engineered for the production of primary flavor determinants in hopped beer. Nat. Commun. 9: 965.

96. Pardo E, Rico J, Gil JV, Orejas M. 2015. De novo production of six key grape aroma monoterpenes by a geraniol synthase-engineered Saccharomyces cerevisiae wine strain. Microb. Cell Fact. 14: 136.

97. Petzold CJ, Chan LJ, Nhan M, Adams PD. 2015. Analytics for metabolic engineering. Front. Bioeng. Biotechnol. 3: 135.

98. Bergman A, Siewers V. 2016. Metabolic engineering strategies to convert carbohydrates to aviation range hydrocarbons, pp. 151190. Biofuels for Aviation, Ed.

99. Hansen ASL, Lennen RM, Sonnenschein N, Herrgard MJ. 2017. Systems biology solutions for biochemical production challenges. Curr. Opin. Biotechnol. 45: 85-91.

100. Thiele I, Palsson BO. 2010. A protocol for generating a high-quality genome-scale metabolic reconstruction. Nat. Protoc. 5: 93-121.

101. Edwards JS, Palsson BO. 1999. Systems properties of the Haemophilus influenzaeRd metabolic genotype. J. Biol. Chem. 274: 1741017416.

102. O’Brien EJ, Monk JM, Palsson BO. 2015. Using genome-scale models to predict biological capabilities. Cell 161: $971-987$.

103. Sandberg TE, Lloyd CJ, Palsson BO, Feist AM. 2017. Laboratory evolution to alternating substrate environments yields distinct phenotypic and genetic adaptive strategies. Appl. Environ. Microbiol. 83: e00410-00417.

104. LaCroix RA, Palsson BO, Feist AM. 2017. A model for designing adaptive laboratory evolution experiments. Appl. Environ. Microbiol. 83: e03115-03116.

105. LaCroix RA, Sandberg TE, O’Brien EJ, Utrilla J, Ebrahim A, Guzman GI, et al. 2015. Use of adaptive laboratory evolution to discover key mutations enabling rapid growth of Escherichia coli K-12 MG1655 on glucose minimal medium. Appl. Environ. Microbiol. 81: 17-30.

106. Strucko T, Zirngibl K, Pereira F, Kafkia E, Mohamed ET, Rettel M, et al. 2018. Laboratory evolution reveals regulatory and metabolic trade-offs of glycerol utilization in Saccharomyces cerevisiae. Metab. Eng. 47: 73-82.

107. Sandberg TE, Long CP, Gonzalez JE, Feist AM, Antoniewicz MR, Palsson BO. 2016. Evolution of Escherichia coli on [U13C]glucose reveals a negligible isotopic influence on metabolism and physiology. PLoS One 11: e0151130.

108. Horinouchi T, Minamoto T, Suzuki S, Shimizu H, Furusawa C. 2014. Development of an automated culture system for laboratory evolution. J. Lab. Autom. 19: 478-482.

109. Toprak E, Veres A, Michel JB, Chait R, Hartl DL, Kishony R. 2011. Evolutionary paths to antibiotic resistance under dynamically sustained drug selection. Nat.Genet. 44: 101-105.

110. Toprak E, Veres A, Yildiz S, Pedraza JM, Chait R, Paulsson J, et al. 2013. Building a morbidostat: An automated continuous-culture device for studying bacterial drug resistance under dynamically sustained drug inhibition. Nat. Protoc. 8: 555-567.

111. Takahashi CN, Miller AW, Ekness F, Dunham MJ, Klavins E. 2015. A low cost, customizable turbidostat for use in Synthetic circuit characterization. ACS Synth. Biol. 4: 32-38.

112. Heins ZJ, Mancuso CP, Kiriakov S, Wong BG, Bashor CJ, Khalil AS. 2019. Designing automated, high-throughput, continuous cell growth experiments using eVOLVER. J. Vis. Exp. 147: 10.3791/59652. 
113. Wong BG, Mancuso CP, Kiriakov S, Bashor CJ, Khalil AS. 2018. Precise, automated control of conditions for high-throughput growth of yeast and bacteria with eVOLVER. Nat. Biotechnol. 36: 614-623.

114. Curran KA, Leavitt JM, Karim AS, Alper HS. 2013. Metabolic engineering of muconic acid production in Saccharomyces cerevisiae. Metab. Eng. 15: 55-66.

115. Kao KC, Sherlock G. 2008. Molecular characterization of clonal interference during adaptive evolution in asexual populations of Saccharomyces cerevisiae. Nat. Genet. 40: 1499-1504.

116. Baba T, Ara T, Hasegawa M, Takai Y, Okumura Y, Baba M, et al. 2006. Construction of Escherichia coli K-12 in-frame, single-gene knockout mutants: the Keio collection. Mol. Syst. Biol. 2: 2006.0008.

117. Domingues L, Teixeira JA, Lima N. 1999. Construction of a flocculent Saccharomyces cerevisiae fermenting lactose. Appl. Microbiol. Biotechnol. 51: 621-626.

118. Kuyper M, Hartog MMP, Toirkens MJ, Almering MJH, Winkler AA, van Dijken JP, et al. 2005. Metabolic engineering of a xyloseisomerase-expressing Saccharomyces cerevisiae strain for rapid anaerobic xylose fermentation. FEMS Yeast Res. 5: 399-409.

119. Herring CD, Raghunathan A, Honisch C, Patel T, Applebee MK, Joyce AR, et al. 2006. Comparative genome sequencing of Escherichia coli allows observation of bacterial evolution on a laboratory timescale. Nat. Genet. 38: 1406-1412.

120. Monk JM, Lloyd CJ, Brunk E, Mih N, Sastry A, King Z, et al. 2017. iML1515, a knowledgebase that computes Escherichia coli traits. Nat. Biotechnol. 35: 904-908.

121. Lu H, Li F, Sanchez BJ, Zhu Z, Li G, Domenzain I, et al. 2019. A consensus Saccharomyces cerevisiae metabolic model Yeast8 and its ecosystem for comprehensively probing cellular metabolism. Nat. Commun. 10: 3586 .

122. Zhang Y, Cai J, Shang X, Wang B, Liu S, Chai X, et al. 2017. A new genome-scale metabolic model of Corynebacterium glutamicum and its application. Biotechnol. Biofuels 10: 169.

123. Kocabaş P, Çalık P, Çalık G, Özdamar TH. 2017. Analyses of extracellular protein production in Bacillus subtilis - II: genome-scale metabolic model reconstruction based on updated gene-enzyme-reaction data. Biochem. Eng. J. 127: 229-241.

124. Lu Y, Ye C, Che J, Xu X, Shao D, Jiang C, et al. 2019. Genomic sequencing, genome-scale metabolic network reconstruction, and in silico flux analysis of the grape endophytic fungus Alternaria sp. MG1. Microb. Cell Fact. 18: 13.

125. Kumelj T, Sulheim S, Wentzel A, Almaas E. 2019. Predicting strain engineering strategies using iKS1317: A genome-scale metabolic model of Streptomyces coelicolor. Biotechnol. J. 14: e1800180.

126. Zuniga C, Levering J, Antoniewicz MR, Guarnieri MT, Betenbaugh MJ, Zengler K. 2018. Predicting dynamic metabolic demands in the photosynthetic eukaryote Chlorella vulgaris. Plant Physiol. 176: 450-462.

127. Ozcan E, Selvi SS, Nikerel E, Teusink B, Toksoy Oner E, Cakir T. 2019. A genome-scale metabolic network of the aroma bacterium Leuconostoc mesenteroides subsp. cremoris. Appl. Microbiol. Biotechnol. 103: 3153-3165.

128. Kristjansdottir T, Bosma EF, Branco Dos Santos F, Ozdemir E, Herrgard MJ, Franca L, et al. 2019. A metabolic reconstruction of Lactobacillus reuteri JCM 1112 and analysis of its potential as a cell factory. Microb. Cell Fact. 18: 186.

129. Loira N, Mendoza S, Paz Cortes M, Rojas N, Travisany D, Genova AD, et al. 2017. Reconstruction of the microalga Nannochloropsis salina genome-scale metabolic model with applications to lipid production. BMC Syst. Biol. 11: 66.

130. Mora Salguero DA, Fernandez-Nino M, Serrano-Bermudez LM, Paez Melo DO, Winck FV, Caldana C, et al. 2018. Development of a chlamydomonas reinhardtii metabolic network dynamic model to describe distinct phenotypes occurring at different $\mathrm{CO}_{2}$ levels. PeerJ. 6: e5528. 